\title{
Busca de consenso entre o direito do autor e o acesso à informação pelo público na rede de computadores: uma ótica dos tratados relativos ao direito autoral
}

Patrícia Pereira Peralta

Doutora em Artes Visuais pela UFRJ.Atua no Mestrado Profissional do INPI, coordenando a disciplina de gestão estratégica de marcas e orientando trabalhos nos campos de marcas e desenho industrial.

Elizabeth Ferreira da Silva

Pesquisador do Instituto Nacional da Propriedade Industrial (INPI).Docente do Mestrado Profissional do INPI

Dirceu Yoshikazu Teruya

Bacharel em Ciências Econômicas pela Universidade Federal do Paraná.Doutor em Integração da América Latina pela Universidade de São Paulo. Pesquisador em Propriedade Industrial do Instituto Nacional da Propriedade Industrial

A evolução da tecnologia da informação e comunicação tem possibilitado a inserção do conteúdo na rede de computadores. No entanto, tem-se criado divergência entre o direito do autor e o acesso à informação. Os tratados e acordos internacionais tentam minimizar essa divergência, mas a dinâmica dos agentes sobre a apropriação do conteúdo é complexa, a ponto das instituições nacionais não conseguirem abordar o objeto por inteiro.

Palavras-Chave: Acesso ao conhecimento; Direito de autor; Tratados sobre direitos autorais.

Search of consensus between the author's right and access to information by the public on network of computers: a perspective of 


\title{
international treaties related to the copyright and the author's right
}

\begin{abstract}
The evolution of information and communication technology has enabled the insertion of content on the Internet. However, this has created divergence between the author's right and access to information. International treaties and agreements attempt to minimize this discrepancy, but the dynamics of the agents on the appropriation of the content is so complex that national institutions cannot address the object as a whole.
\end{abstract}

Keywords: Access to knowledge; Author's right; Treaty concerning author's right.

Recebido em 18.10.2010 Aceito em 30.07.2011

\section{Introdução}

A geração de ideias tem sido realizada em uma velocidade cada vez maior, por conta da capacidade criativa dos agentes e por conta do processo de difusão do conhecimento e da obra de seus criadores. Em parte, essa geração tem sido estimulada pela necessidade de atendimento ao mercado e, de outro lado, pela disseminação de ideias, sem necessariamente auferir ganhos econômicos. Ao mesmo tempo, tem-se que o desenvolvimento tecnológico, na área de tecnologia de informação, tem propiciado uma disseminação cada vez mais instantânea da informação. Contudo, a tensão entre a disseminação livre de informação e os conteúdos apropriados por direitos de propriedade intelectual, vem levando a busca de um consenso entre o direito do autor e o interesse do público no acesso, uma vez que o criador do conteúdo precisa ter sua obra protegida e, ao mesmo tempo, garantir que a obra seja objeto de uso pela sociedade. No entanto, a relação entre o direito autoral e o interesse do público ainda é divergente, pois, pelo lado do autor, este necessita ser remunerado adequadamente pela concepção da obra. A outra parte necessita de informações e conteúdo promovido pelo autor, para subsidiar sua capacitação e/ou o desenvolvimento de negócios.

Ao mesmo tempo, o acesso à informação e à obra do autor tem sido rapidamente disseminado na rede de computadores, o que tem proporcionado novos modos de relacionamento entre os agentes e, ainda, a necessidade de uma regulamentação dessas relações. A regulação nacional e os tratados internacionais são mecanismos para a busca de consenso das relações entre o interesse do público e o direito do autor, relacionado ao conteúdo disponibilizado na rede de computadores, pois 
esses mecanismos tentam atender às necessidades de cada parte no processo, cada vez mais intenso, de troca de conteúdo na era digital.

O objetivo deste trabalho é verificar a importância e a relevância dos tratados internacionais sobre direitos autorais, como meio de promoção ou criação de consenso entre o direito do autor e o interesse do público.

A metodologia deste trabalho será analítica e descritiva a respeito dos tratados internacionais sobre direito autoral, sob uma perspectiva do papel de promoção ou criação de um ambiente de consenso entre as partes envolvidas, no conteúdo disponibilizado na rede de computadores.

Este trabalho apresenta a seguinte estrutura: primeiramente, farse-á um breve embasamento teórico, baseado no direito autoral e seu conteúdo cerceador, referente ao acesso do público. Na segunda parte, discutir-se-á a rede de computadores como meio de inserção de conteúdo pelo autor e disponibilização desse conteúdo informacional ao público. Na terceira parte, far-se-á uma discussão dos tratados internacionais da Convenção Unionística de Berna (CUB), o Acordo sobre Aspectos dos Direitos de Propriedade Intelectual relacionados ao Comércio (TRIPs), Tratado de Copyright da Organização Mundial da Propriedade Intelectual (WTC) e Tratado de Performance e Fonograma da Organização Mundial da Propriedade Intelectual (WPPT) e a busca de consenso na relação entre direito do autor e o interesse do público. Por fim, apresentar-se-á uma conclusão dos itens discutidos anteriormente.

\section{Direito de autor: uma breve discussão teórica}

A expressão "direitos de autor" visa a abarcar os direitos que incidem sobre as obras da criatividade humana, tendo em vista a potencial relevância econômica que tais obras passaram a ter. Para essa expressão é comum, também, o uso da terminologia direitos autorais, tendo sido esta cunhada por Tobias Barreto, ainda no início do século XX. Para Bittar (2008, p. 8):

[...] o Direito de Autor ou Direito Autoral é o ramo do Direito Privado que regula as relações jurídicas, advindas da criação e da utilização econômica de obras intelectuais estéticas e compreendidas na literatura, nas artes e nas ciências. [...] As relações regidas por esse Direito nascem com a criação da obra, surgindo, do próprio ato criador, direitos respeitantes à sua face pessoal (...) e, de outro lado, com sua comunicação ao público, os direitos patrimoniais [...]

Para Ascensão (2007, p. 3), a criação autoral se assemelha à criação divina: o homem cria "à semelhança de Deus". Por isso, segundo o autor citado, a criação humana pode ser considerada uma atividade extremamente nobre e merecer a "tutela conferida pelo Direito de Autor, [sendo esta] a mais extensa e a mais apetecida de todas as tutelas dentro dos direitos intelectuais". 
Pode-se colocar que, atualmente, existem dois sistemas de proteção autoral: o citado direito de autor ou direito autoral e o Copyright. O primeiro é fruto do sistema continental europeu, bem como de sua evolução, sendo o elemento primordial desse sistema a proteção do autor $^{1}$. O último visa à proteção da obra, ficando claro este objetivo na tradução literal que pode ser feita do termo estrangeiro - copyright, ou melhor, direito à cópia. A diferença, que parece sutil, marca profundamente os dois sistemas, levando a modificações na forma de negociação das obras em função dos direitos morais do autor, que encontram abrigo nas legislações de direitos autorais, mas estão ausentes na proteção conferida pelo copyright ${ }^{2}$.

Para os fins deste artigo, é importante que seja destacada apenas as terminologias direito de autor ou direito autoral, e não copyright, tendo em vista que as primeiras terminologias são predominantes na maior parte dos países do mundo, bem como no Brasil. Segundo o sistema autoralista, a proteção dos direitos autorais recai sobre todas as criações do domínio literário e artístico que possam ser tangibilizadas de alguma forma. Este é o princípio norteador advindo da Convenção da União de Berna, a primeira Convenção Internacional a estabelecer diretrizes e padrões mínimos de proteção às obras autorais para todos os partícipes da União.

Segundo Ascensão (2007, p. 27), "o Direito de Autor tutela necessariamente criações do espírito", mas tais criações devem ser materializadas, sem que este ato de materialização seja confundido com aquilo que se deve proteger, ou seja, a obra.

Se repudiamos a tentação idealística e distinguimos a obra da idéia, devemos repudiar a tentação materialística, não confundindo a obra com o suporte material que a encerra. A este se chama o corpus mechanicum, mas parece-nos a expressão inadequada e dispensável, pelo que vamos evitar (ASCENSÃO, 2007, p. 31).

A abrangência da proteção do que se entende por direito de autor tem sido acrescida. Inicialmente, na década de 1960, passaram a ser protegidos por direitos conexos ao direito de autor os intérpretes, artistas,

Ascensão (2007, p. 4) apresenta a questão: "Na realidade, o que esta lei concedeu foi um privilégio de reprodução: 'shall have the sole right and liberty of printing such books'. Surge assim a visão angloamericana do copyright, que nunca foi abandonada. Na base, estaria a materialidade do exemplar e o exclusivo da reprodução deste. No mesmo século XVIII, porém, no continente europeu, caminhou-se noutra direção. Embora se recorresse também à figura do privilégio, centrou-se a tutela na actividade criadora em si, mais que na materialidade do exemplar. Foi essa a situação que encontrou a Revolução Francesa, que pretendeu a supressão de todos os privilégios. Como tutelar então os autores? $\mathrm{O}$ caminho seguido foi o da afirmação de uma propriedade do autor sobre a obra, aproveitando a sacralização que àquele direito se outorga. O direito de autor seria até a mais sagrada de todas as propriedades. Mesmo assim, a confusão entre a obra e a sua materialidade subsistiu durante muito tempo".

Ainda Ascensão (2007, p. 5): "De toda a maneira, o sistema continental europeu é o sistema chamado de direito de autor, assente na tutela do criador. Este sistema coexiste no plano internacional, mediante composições muitas vezes semânticas, com o sistema anglo-americano do copyright. Porque centrado na tutela do exemplar, o sistema anglo-americano admite largamente que o direito de autor seja atribuído à empresa, embora só a lei americana acolha a noção de obra colectiva". 
executantes, os produtores de fonograma e as empresas de radiodifusão, através de nova Convenção Internacional denominada Convenção de Roma. Mais recentemente, foram os programas de computador a serem inseridos no escopo de bens protegidos por direitos de autor. Entretanto, tais programas passaram a contar com legislação própria.

O objeto de proteção do direito de autor envolve bens culturais, sendo esses de interesses de fruição por boa parte da sociedade e, assim, se chega à problemática na qual se encontra a discussão autoral na atualidade, entre os interesses dos autores de perceberem valores econômicos pela exploração comercial de suas criações e do público de ter acesso, cada vez mais rápido e simplificado, aos bens culturais de criação autoral.

Para Wachowicz (2004, p. 216):

[...] o desenvolvimento e a difusão da tecnologia da informação na sociedade informacional acarretam um impacto ambivalente na proteção dos direitos autorais, que podem ser mensurados por vários aspectos: o primeiro, é que esta tecnologia digital proporciona a expansão da reprodução de obras não autorizadas; em segundo, permite por meio de mecanismos tecnológicos limitar estas reproduções; e, por último, a mesma tecnologia digital oferece o livre acesso e uso das informações que circulam pela rede.

As exceções previstas na Convenção de Berna, aos direitos de autor, permitem alguns usos, como aqueles para fins educacionais. Entretanto, as mesmas não foram adotadas por todos os países membros da Convenção, como é o caso do Brasil, que trabalha com limitações muito modestas e extremamente limitadoras do interesse do público ao acesso. O impasse posto vem provocando movimentos por parte da sociedade ${ }^{3}$ na tentativa de garantir o seu direito à informação e cultura ${ }^{4}$, mas o consenso esperado ainda não parece ter se delineado. Na próxima sessão, será discutido o acesso à informação pela rede de computadores decorrente do desenvolvimento tecnológico.

\section{Redes de computador: acesso das informações}

São exemplos desse movimento, as iniciativas do Ministério da Cultura brasileiro, na reformulação da legislação de direitos autorais, buscando um equilíbrio entre a proteção autoral e os interesses da sociedade em ter acesso à informação e o movimento Creative Commons, que busca a construção de um sistema de licenças concedidas pelos próprios autores, para o material disponibilizado na grande rede de computadores.

4 Direito este concedido pela Constituição Federal do Brasil que, no seu artigo $5^{\circ}$., dos direitos fundamentais, inciso XIV, garante a todos o "[...] acesso à informação [...]", e no seu artigo 215 garante o "[...] pleno exercício dos direitos culturais e acesso às fontes da cultura nacional $[. .] "$. 
O desenvolvimento tecnológico tem proporcionado a criação de novos produtos e serviços, bem como a alteração da estrutura produtiva e o surgimento de novos modelos de negócios (PEREZ; FREEMAN, 1988). Nesse sentido, o paradigma microeletrônico ${ }^{5}$ tem possibilitado 0 desenvolvimento de um ambiente virtual para inserção de informações, cuja abrangência atinge a economia como um todo. Esse padrão técnicoeconômico provocou transformações estruturais na economia, sendo cada vez mais intensa e mais rápida a incorporação do progresso tecnológico na esfera produtiva e comercial, conduzindo a uma nova era na economia - a Era do Conhecimento. Na economia do conhecimento ${ }^{6}$, o acesso à informação torna-se vital para a criação de riqueza e geração de receita na sociedade atual, o que marca, decisivamente, a passagem do processo de acumulação de riqueza dos bens tangíveis para os intangíveis, onde informação e conhecimento são os elementos da nova dinâmica competitiva baseada na inovação. Assim, o processo de geração e difusão de conhecimentos é visto como o motor do desenvolvimento econômico, estabelecendo...

novas práticas de produção, comercialização e consumo de bens e serviços, cooperação e de competição entre os agentes, assim como de circulação e de valorização do capital, a partir da maior intensidade de uso de informação e conhecimento desses processos (LASTRES; ALBAGLI, 1999, p. 8).

Segundo Castells (2000), a informação se articula e se coaduna com as Tecnologias de Informação e Comunicação (TIC) ${ }^{7}$, operando uma mudança estrutural na economia, com alto poder de irradiação de seus efeitos para todos os demais setores da economia, com ênfase, cada vez maior, nos setores intensivos em informação e conhecimento.

Nesse contexto, o termo TIC aponta a convergência entre as diversas áreas tecnológicas ${ }^{8}$, que lidam com 0 armazenamento, tratamento e transmissão da informação, apoiado pelos avanços tecnológicos do paradigma da microeletrônica, que permitiu um maior condensamento, uma maior velocidade, confiabilidade, associados a um

Dessa forma, o paradigma da microeletrônica atende à questão de sua ampla aplicabilidade na economia, demanda crescente, redução custo unitário aliado a uma crescente capacidade técnica, servindo como suporte ferramental para a evolução e desenvolvimento da tecnologia da informação.

A criação de valor, a partir das fontes intangíveis, é dependente do gerenciamento individual de cada firma e da implementação específica de suas estratégias de negócio, assim como de sua capacidade de aprendizado, de absorção, difusão, de aquisição e geração de conhecimento. Dessa forma, o conhecimento se torna o diferencial competitivo e ganha a dimensão de um ativo que deve ser gerenciado e retido, como forma de manter o diferencial competitivo entre as firmas (ORGANIZATION FOR ECONOMIC COOPERATION AND DEVELOPMENT - OECD, 2007)

As TICs operam mudanças nos diversos níveis de inovação (técnica, organizacional e institucional), sendo, ao mesmo tempo, o motivo e o ferramental para a mudança no ambiente de gestão do negócio, assim como influenciando os novos modelos, formatos e estratégias de negócios em todos os níveis (empresarial, centros de ensino, pesquisa e administração pública), demandando crescentemente um fluxo de informação e conhecimento para a operacionalidade dos seus próprios sistemas de negócio e, portanto, sendo dependentes da informação e do conhecimento (LASTRES; ALBAGLI, 1999).

8 O termo tecnologia da informação engloba as áreas de informática, telecomunicações, comunicações, ciência da computação, engenharia de sistemas e de software. 
menor custo de transmissão, disseminação, armazenamento e processamento de um maior volume de dados e outras informações (LASTRES; ALBAGLI, 1999). Indubitavelmente, as TICs aumentam a tendência de codificação da informação e a possibilidade de sua disseminação.

O surgimento da rede mundial de computadores, a Internet ${ }^{9}$, é decorrente desse fenômeno, sendo o motor propulsor do fluxo e da disponibilidade de acesso à informação e ao conhecimento, proporcionando inúmeras possibilidades de formatos de novos negócios, reduzindo as barreiras da distância física e temporal entre os agentes econômicos e, ainda, reduzindo os custos das transações. Segundo Castells (2000, p. 414):

A integração potencial de texto, imagens e sons no mesmo sistema - interagindo a partir de pontos múltiplos, no tempo escolhido (real ou atrasado) em uma rede global, em condições de acesso aberto e de preço acessível - muda de forma fundamental o caráter da comunicação. E a comunicação, decididamente, molda a cultura [...] 0 surgimento de um novo sistema eletrônico de comunicação caracterizado por seu alcance global, integração de todos os meios de comunicação e interatividade potencial está mudando e mudará para sempre a nossa cultura.

A concepção de uma arquitetura de rede aberta e flexível sempre esteve presente, desde os primórdios da existência da Internet, apesar de ter sido criada, inicialmente, para fins militares. $O$ caráter descentralizado ${ }^{10}$ do sistema foi a opção adotada como estratégica militar para sua implementação, a fim de evitar o caos no sistema norteamericano de comunicação, frente a um ataque nuclear. Essa própria concepção de rede aberta já anunciava o dinamismo do próprio fluxo da informação e conhecimento, sendo esse fluxo reforçado pelo processo da globalização, da interatividade entre as diferentes nações e culturas e pelos avanços tecnológicos, que permitiriam a reprodutibilidade e transmissão de conteúdos.

Outro fator decisivo foi o estabelecimento das primeiras descentralizações ${ }^{11}$ (nós ou centros) estarem associadas às Universidades, influenciando diretamente o comportamento das sucessivas gerações que por ali passam, e, portanto, o padrão de comunicação de uma sociedade.

\footnotetext{
9 "A Internet foi uma iniciativa norte-americana de âmbito mundial encetada , com apoio militar, por empresas de informática financiadas pelo governo norte-americano, para criar um clube mundial de usuários de computadores e banco de dados" (CASTELLS, 2000, p. 428).

10 Outro fator decisivo foi o estabelecimento das primeiras descentralizações (nós) estarem associadas às Universidades norte-americanas. Esses centros pertinentes à comunidade acadêmica foram essenciais para o desenvolvimento e difusão da comunicação eletrônica no mundo.

11 O comportamento inicial da comunicação global mediada por computadores, proposto pela rede americana, cujo modelo de descentralização ocorreu a partir das universidades, foi seguido pelo restante do mundo, nas décadas seguintes. . Esses centros pertinentes à comunidade acadêmica foram essenciais para o desenvolvimento e difusão da comunicação eletrônica no mundo, sendo o cerne da difusão de um processo de inovação social (CASTELLS, 2000).
} 
A conformação da rede baseada na comunicação mediada por computadores e sua inserção inicial no ambiente acadêmico, associada à questão da livre acessibilidade, foram decisivos para a disseminação do uso da Internet e para a cultura do fluxo do conhecimento livre, fruto de um esforço coletivo, portanto um bem livre e não privado, formando um ambiente de cooperação e a crença do conhecimento compartilhado. Dessa forma, a informação é tratada como um insumo para ser disponibilizado, transferido, disseminado e aprimorado na Internet, desvinculado de um suporte físico qualquer que lhe desse a tangibilidade e, portanto, pudesse determinar sua escassez, nos moldes tradicionais dos bens tangíveis.

Nesse sentido, o pressuposto da acessibilidade da informação e de novas modalidades do processo inovador tem sido proporcionado pela própria concepção aberta da Internet, pela penetrabilidade e aceitação da rede pela sociedade e pelo aporte tecnológico (CASTELLS, 2000).

Ademais, os primeiros ingressantes no sistema determinam a própria configuração da rede, devido seu caráter interativo - consumo e fornecimento de conteúdo, proporcionando uma ação individualizada entre seus participantes, de acordo com suas necessidades e anseios comerciais. A rede mundial de computadores (cujo seu interior abarca uma rede de instituições, associações, empresas, pessoas físicas e outras entidades) constitui formas de interação entre os agentes (CASTELLS, 2000).

Na lógica da Internet, o valor está na capacidade de geração de riqueza econômica, por meio da apropriação das informações disponibilizadas pelos agentes, bem como a capacidade de trabalho em redes abertas. Além disso, o avanço tecnológico das TICs tem promovido uma redução de custos de transação, permitindo a criação de novos modelos de negócios que envolvem bens tangíveis e intangíveis(direitos sobre propriedade, tais como a propriedade intelectual e know how ).

Cabe ressaltar a natureza distinta entre a informação e o conhecimento. A informação está associada à codificação do conhecimento (conhecimento estruturado e sistematizado), cabível, portanto, de ser reproduzido, estocado, transferido, adquirido, comercializado, ou seja, transacionado. Entretanto, existe outra forma de conhecimento, o conhecimento tácito, que está associado ao processo de aprendizado, sendo dependente do contexto sóciopolítico-econômico, cultural e das interações específicas dos grupos em estabelecer suas competências, habilidades e eficiência e eficácia técnico-produtiva (CASSIOLATO et al., 2005), sendo, portanto, difíceis de serem transmitidos e transferíveis e, ao mesmo tempo, sendo determinantes para $o$ entendimento $e$ decodificação do conhecimento codificado.

A importância do conhecimento, como agente transformador do processo de produção, pode, também, ser um fator indutor desse processo crescente de codificação do conhecimento e de sua possível transação econômica ou distribuição, reforçando a tendência atual de sua apropriação e tentativa de transformá-lo em um bem privado. De 
qualquer forma, há características básicas que diferenciam os bens tangíveis dos bens intangíveis, as quais mostram e sinalizam uma incompatibilidade de tratá-los, a priori, sob a ótica tradicional dos bens tangíveis e, portanto, de sua apropriação.

Assim, a propriedade intelectual apresenta-se como um instrumento para proporcionar a proteção do intelecto humano, bem como garantir ganhos econômicos pelos agentes envolvidos em transações de licenciamento de direitos de propriedade intelectual, que envolve o direito autoral nessa nova dinâmica da sociedade do conhecimento.

Ao mesmo tempo, surge a discussão da dicotomia no cerne da proposição de um consenso entre o interesse do autor e o interesse público, uma vez que a sociedade necessita do acesso a esta informação e o conteúdo gerado necessita remunerar o criador.

A remuneração do esforço criativo do autor não necessariamente contrapõe o acesso ao conhecimento pela sociedade, mesmo que o conteúdo seja hospedado na Internet. A questão da fácil reprodutibilidade, praticamente sem custo, do conteúdo disponibilizado na Internet, possibilita a ocorrência da duplicação ilegal da obra. Esta situação tem dificultado o autor a gerir os ganhos advindos da exploração de sua obra (controle sob venda, comercialização e qualquer outro tipo de transação).

Em contrapartida, os avanços tecnológicos têm criado mecanismos de controle e segurança, que impedem a cópia sobre o material digital, sem a devida remuneração sobre o conteúdo.

Assim, a rede global de computadores tem sido foco de disputas e conflitos que envolvem a questão dos materiais protegidos por legislações de direitos autorais. Além disso, entre os produtos da criação humana, há conteúdos que podem ser utilizadas com fins educacionais ou de entretenimento. Na verdade, tal conteúdo tem valorizado a importância que a rede assumiu para muitos dos seus usuários, uma vez que o acesso a textos científicos ou às mídias de música e vídeo permitiu que muitos usuários pudessem ter contato com obras de diferentes localidades.

As atuais discussões relativas ao acesso do material protegido ${ }^{12}$ por direito autoral, na rede, conduzem a um aparente impasse entre 0 interesse público e privado, pelo menos na atual conjuntura. A demanda pelos usuários da rede por alternativas de uso que não sejam taxadas de violadoras de direitos de terceiros encontra cada vez mais repercussão entre os usuários da Internet, sobretudo, entre os países subdesenvolvidos. Dentro do que hoje está protegido por direitos autorais, encontram-se as obras literárias, artísticas, científicas e os programas de computador (estes compreendidos como obras literárias).

A complexidade desse contexto encontra-se, também, nas especificidades e particularidades pertinentes a cada legislação local e na tentativa de se construir mundialmente tratados internacionais, que garantam um mínimo de padrão de proteção aos titulares de tal direito,

12 Entretanto, há questões alarmantes quanto ao uso ilícito da Internet que atingem a sociedade, tais como os casos de pedofilia e desvio de dados, inclusive de valores monetários, praticados pelos denominados hackers. 
sendo crucial essa questão pelo fato do fluxo de disseminação do conhecimento pela Internet. Na próxima seção, serão apresentados os tratados internacionais, inclusive, contrapondo-se as questões da flexibilidade do direito de autor contidas no primeiro tratado internacional de direito de autor, o Tratado de Berna, via regra dos três passos, e o atual cenário de enforcement do Acordo sobre os Aspectos da Propriedade Intelectual no Comércio Internacional (TRIPs), além do Tratado de Copyright da Organização Mundial da Propriedade Intelectual (WTC) e Tratado de Performance e Fonograma da Organização Mundial da Propriedade Intelectual (WPPT).

\section{Tratados internacionais e a busca de consenso entre o direito do autor e o interesse público}

A necessidade de consenso é buscada como forma de diminuir as incertezas e a promoção do desenvolvimento econômico dos países. Dessa forma, desde o fim do século XIX, tem-se realizado um esforço entre os agentes, na busca de consenso entre o direito do autor e o acesso à informação, nos quatro principais tratados relativos a esta temática.

O primeiro tratado é a Convenção Unionística de Berna (CUB) ${ }^{13}$. Esta convenção foi assinada de forma multilateral, que definiu o escopo e abrangência de proteção relativa ao direito de autor. Em princípio, a CUB procurava garantir a proteção das então denominadas Belas Artes (pintura, escultura, gravura, arquitetura), das obras literárias (livros em toda a generalidade de seus temas e peças teatrais), sendo incorporadas, mais tarde, as obras científicas.

Este acordo prevê uma flexibilização das regras, de modo a adequálo ao estágio do desenvolvimento econômico de cada nação, tentando contemplar os interesses dos titulares dos direitos e da sociedade em questão. Nesse contexto, a regra dos três passos é o mecanismo que norteia as exceções ou atenuações para as questões de infrações de direito. No que tange ao direito de autor, os avanços tecnológicos abriam espaços para novas demandas de proteção no âmbito artístico e literário, tais como o surgimento da fotografia, rádio e televisão, o que culminou no surgimento da Convenção de Roma (1961) ${ }^{14}$. Em face da evolução tecnológica, foi promovida a inserção do programa de computador, sob a tutela do direito de autor e da proteção de base de dados e, também, sob a ótica do direito autoral, mas como obra derivada (apresentação de um esforço intelectual na forma de agrupamento de dados, mas não sobre a originalidade do conteúdo em si, como era o caso, também, das enciclopédias).

A Convenção Unionística de Berna foi assinada em 09 de setembro de 1886, e tem sido complementada e revisada ao longo do século XX. Esta convenção esta sob a gerência da Organização Mundial da Propriedade Intelectual.

14 Essa convenção foi uma resposta à demanda de proteção de artistas, intérpretes, produtores de fonograma e organismos de radiodifusão, em função da pressão das inovações tecnológicas geradas pelo advento do rádio e da televisão, que possibilitavam uma maior extensão da disponibilidade do conteúdo de cunho autoral. 
Entretanto, na medida em que a importância do conhecimento avança nas relações produtivas, há uma alteração no padrão de acumulação de riqueza - uma quebra de paradigma entre os bens tangíveis e intangíveis. O conhecimento é um ativo intangível, impulsionador de desenvolvimento, que cada vez mais necessita ser codificado, apropriado para ser negociado. E, é nesse contexto, que os novos acordos internacionais sobre propriedade intelectual são estruturadas suas diretrizes, dependentes das entidades que os administram e dos seus consequentes interesses.

Um dos mais importantes e controversos acordos na esfera internacional foi o Acordo sobre os Aspectos da Propriedade Intelectual no Comércio Internacional (TRIPs), administrado pela Organização Mundial do Comércio, que eleva os padrões do nível mínimo de proteção, além de estender a proteção a todos os campos tecnológicos, inclusive aos novos possíveis campos.

Em 1994, como parte da relação da propriedade intelectual e o comércio internacional, tem-se a ratificação pelos membros do Acordo Geral de Comércio e Tarifas (GATT) do Acordo de Marrackesh, que apresenta um de seus anexos de TRIPs. Este acordo, no caso específico do direito de autor, busca um maior rigor a respeito da abrangência e da proteção definida pela Convenção Unionística de Berna, aos membros do acordo, com direito a retaliações aos países signatários que não cumpri-lo, segundo os critérios da Organização Mundial do Comércio (OMC), à luz do mecanismo de solução de controvérsia.

Dessa forma, esta uniformização mínima, a aplicação da CUB pelos membros, diminui a assimetria da informação dos princípios dos membros do GATT ao escopo e abrangência do direito de autor. Além disso, este acordo ratifica os princípios da nação mais favorecida ${ }^{15}$ e o tratamento nacional ${ }^{16}$, bem como relaciona a propriedade intelectual ao comércio internacional, estabelecendo-se um mecanismo de imposição de direito. Assim, uma infração de direitos de propriedade intelectual pode gerar sanções econômicas, como, também, um conflito econômico pode permitir retaliações no campo da propriedade intelectual. Em contrapartida, este acordo não leva em consideração as particularidades e o estágio de desenvolvimento econômico dos países.

A partir da consolidação do TRIPs, houve a discussão e a ratificação de dois tratados: o primeiro é o Tratado de Copyright da Organização Mundial da Propriedade Intelectual (WTC) e o segundo é o Tratado de Performance e Fonograma da Organização Mundial da Propriedade Intelectual (WPPT). Ambos administrados pela Organização Mundial da Propriedade Intelectual (OMPI), na tentativa de adequar a legislação atual às novas formas de utilização de obras protegidas.

15 O princípio da nação mais favorecida está relacionado ao fato de que nenhum membro do Acordo Geral de Comércio e Tarifas (GATT) e da Organização Mundial do Comércio terá privilégio diferenciado.

16 O tratamento nacional é uma regra não discriminatória relacionada com a equivalência do tratamento entre o bem importado e o similar nacional. No caso da propriedade intelectual, não há discriminação entre direito de residente e não residente. 
O WTC tem como objetivo tornar a legislação autoral mais condizente com os novos usos de produtos protegidos por direitos autorais em função das novas tecnologias. Com uma redação não muito extensa, o tratado mantém as principais diretrizes presentes na CUB. Como sua própria denominação expressa, o seu conteúdo refere-se aos direitos de autor, não abordando os direitos conexos, que serão tratados no WPPT.

Assim, o WCT prevê a proteção dos programas de computador como obras literárias, remetendo para a definição de obras literárias constante da CUB. Pela primeira vez, um tratado sobre direitos autorais faz referência à locação de obras protegidas ${ }^{17}$, o que possibilita a constituição de modelos de negócios. Também tem-se a inserção da proteção das bases de dados como matéria protegida, desde que as mesmas possuam uma organização ou disposição que indique originalidade. Além disso, incorpora-se neste tratado, as obrigações concernentes às medidas tecnológicas e obrigações concernentes sobre informações relativas ao gerenciamento de direitos.

Nesse sentido, cada país signatário do tratado da OMPI deverá prever proteção legal eficiente, sobre os mecanismos tecnológicos utilizados por seus autores na criação e na disponibilidade de suas obras, prevendo sanções jurídicas eficazes contra aqueles que neutralizarem as medidas técnicas postas pelos autores ${ }^{18}$. Os membros do tratado também se comprometem a prever instrumentos legais contra terceiros, que removam os mecanismos eletrônicos de controle e gerenciamento do material protegido pelo autor, bem como, também, aqueles que vendam, distribuam ou disponibilizem materiais protegidos por direitos autorais e dos quais tenham sido removidos, sem a autorização do autor, os dispositivos de controle de informações de gerenciamento de direitos.

Pelo que pode ser observado, o presente tratado introduz ao sistema de propriedade intelectual mecanismos tecnológicos de controle do material protegido por direitos autorais e de impor sanções civis, entre outras, sobre aqueles que tentarem retirar tais mecanismos de proteção e gerenciamento de informação sobre os direitos autorais. Além das inovações descritas acima, os demais artigos presentes no WCT apenas reforçam as ideias já contidas na Convenção de Berna.

O WIPO Performances and Phonograms Treaty (WPPT) aborda alterações referentes aos direitos vizinhos ou conexos ao do autor, complementando o WCT e fazendo referências às disposições encontradas na Convenção de Roma, que abriga a proteção aos artistas, intérpretes, produtores de fonograma e aos organismos de radiodifusão. A data de sua implantação foi, também, o ano de 1996.

Tratando diretamente do arcabouço legal presente no WPPT, destaca-se a regulação do aluguel de material protegido pelos direitos conexos. Assim como no WCT, tem-se a possibilidade de disponibilidade do material protegido pelo titular dos direitos, através de transmissões com ou sem fio, como pode ser observado na citação a seguir:

\footnotetext{
17 Esta regulamentação pode ser observada no artigo 70 do WTC.

18 Esta disposição está no artigo 11 do supracitado acordo.
} 
Les artistes interprètes ou exécutants jouissent du droit exclusif d'autoriser la mise à la disposition du public, par fil ou sans fil, de leurs interprétations ou exécutions fixées sur phonogrammes, de manière que chacun puisse y avoir accès de l'endroit et au moment qu'il choisit individuellement ${ }^{19}$

O WPPT, assim como o WCT, assemelha-se em relação às medidas tecnológicas a serem utilizadas pelos detentores dos direitos conexos, na tentativa de proteger o material por eles produzidos ou veiculados. Tais inovações estão presentes nos artigos 18 (obrigações relativas às medidas técnicas) e 19 (obrigações relativas à informação sobre o regime de direitos).

O artigo 18 dispõe que as partes contratantes devem prever uma proteção jurídica apropriada e sanções jurídicas eficazes contra a neutralização das medidas técnicas que são postas nas obras pelos artistas intérpretes e executantes ou pelos produtores de fonograma. Tal medida visa a determinar que tipo de uso poderá ser feito com o material protegido pelo usuário do mesmo, que tem seu uso restringido pelo detentor dos direitos. Essa postura de proteção visa a recair principalmente sobre o material posto na rede de computadores e a criar várias dificuldades sobre o controle do uso que estão fazendo sobre o mesmo.

Já no artigo 19, as partes devem prever sanções jurídicas apropriadas e eficazes contra toda pessoa que suprimir ou modificar, sem estar habilitado, toda informação relativa ao regime dos direitos apresentados sobre forma eletrônica e/ou distribuir, importar com fins de distribuição, radiodifundir, comunicar ao público ou colocar à disposição do público - sem ter sido habilitado - as interpretações ou execuções, cópias de interpretação ou execução fixadas ou, ainda, dos exemplares de fonogramas dos quais tenham sido suprimidos ou modificados os dispositivos eletrônicos de controle dos direitos dos titulares.

Mais uma vez, percebe-se a necessidade de se criar mecanismos não só de proteção, como, também, de controle sobre o uso de material protegido por direitos de cunho autoral ou conexo, em função do uso massificado desses, nas grandes estradas da informação.

Os acordos e tratados são resultados de consensos relacionados à dinâmica das relações sociais, econômicas e do avanço da tecnologia, que alteram a configuração da apropriação do conhecimento para geração de riqueza, bem como gera a necessidade de uma proteção aos autores para que se crie as condições de serem devidamente remunerados pela sua artividade.

No entanto, eles não são suficientes para promover um consenso, $a$ priori, entre o acesso à informação e o direito de autor, pois estas relações tornam-se cada vez mais complexas em um ambiente de rede de computadores, onde o acesso à informação tem sido facilitado. Dessa

$19 \quad$ Artigo 10 do WPPT. 
forma, os tratados e acordos necessitam ser regulados por marcos regulatórios nacionais, de forma a garantir segurança jurídica para as relações entre os agentes econômicos e a diminuição da incerteza no processo criativo.

\section{Conclusão}

O consenso entre o direito do autor e o acesso à informação tem sido construído ao longo do tempo, mas como pode ser observada neste texto, a divergência entre o direito de autor e do público emerge da constatação inerente da natureza entre os tipos de material protegido, onde a especificidade do resultado do produto criativo do homem torna-o protegido por direito autoral e, portanto, determina o seu tipo de distribuição e acesso, embora o material em si, tenha especificidade distinta, que pode nortear usos e finalidades diferentes entre os usuários. O grupo de produtos intangíveis produzidos pelo espírito humano possui diferenças e especificidades, que devem ser incorporadas aos direitos autorais e à proteção às criações do espírito humano.

A finalidade e o uso do conteúdo produzido pelo intelecto humano, disponibilizado na rede de computadores, poderia amenizar as questões da acessibilidade aos conteúdos, tanto que já foi motivo de flexibilização, no início da formulação dos tratados internacionais, referente ao direito de autor, conforme observava o Tratado de Berna, via regra dos 3 passos. Entretanto, atualmente, o que se nota é que estes mecanismos estão sendo cada vez mais restringidos, frente ao peso do valor da informação, no cenário econômico atual e aos sucessivos avanços tecnológicos associados à TI (facilidade de reprodutibilidade e acesso à obra).

O espaço de comercialização dos bens na Internet parece ser, em princípio, um processo irreversível e, portanto, a tendência é que cada vez mais haja a circulação do conhecimento além das fronteiras nacionais e, também, que haja necessidadede criação de instituições que possam dar suporte na solução das divergências

Os tratados e acordos internacionais analisados, neste artigo, buscam criar elementos para consenso, mas os interesses nacionais e o rápido desenvolvimento das TICs dificultam a implementação de marcos institucionais nacionais, para que diminua a incerteza dos agentes econômicos no investimento, na criação do intelecto humano e na promoção da difusão desta criação.

O consenso entre o direito de autor e do interesse público é dependente da possibilidade de especificidades relacionadas ao ganho econômico e ao acesso à informação, desde que eles sejam discutidos pela sociedade; e as convergências de interesses entre os agentes sejam resultado de concertações sociais, que envolvam flexibilização da reprodutibilidade de seu conteúdo e que sejam adotados modelos de negócios distintos, respeitando-se essa especificidade, de acordo com sua finalidade de uso. 


\section{Referências}

ASCENSÃO, J. O. Direito autoral. Rio de Janeiro: Renovar, 2007.

BITTAR, C. A. Direito de autor. São Paulo: Forense Universitária, 2008.

CASSIOLATO, J. E. et al. Innovation Systems and development: what can we learn from Latin América experience? GLOBELICS CONFERENCE, 3., 2005. Proceedings... Pretoria, South America, 2005. p. 1-22.

CASTELLS, M. A sociedade em rede. São Paulo: Paz e Terra, 2000.

CONVENÇÃO de Roma. Disponível em: $<$ http://www.wipo.int/treaties/en/ip/rome/trtdocs wo024.html>. Acesso em: 20 set. 2010.

CONVENÇÃO UNIONÍSTICA DE BERNA (CUB). Disponível em: $<$ http://www.wipo.int/treaties/en/ip/berne/trtdocs wo001.html>. Acesso em: 20 set. 2010.

ACORDO GERAL DE COMÉRCIO E TARIFAS (GATT). Disponível em: $<$ http://www.wto.org/english/docs e/legal e/gatt47 e.pdf>. Acesso em: 20 set. 2010.

LASTRES, H.; ALBAGLI, S. Informação e globalização na era do conhecimento. Rio de Janeiro: Campus, 1999.

ORGANIZATION FOR ECONOMIC CO-OPERATION AND DEVELOPMENT (OECD). Creating Value From Intellectual Assets. Policy Brief. Organization for Economic Co-Operation and Development,. Fev-2007. p. 1-8. Disponível em: <www.oecd.org/dataoecd/8/45/38194512.pdf>. Acesso em: 20 set. 2010.

PEREZ, C.; FREEMAN, C. Structural crises of adjustment, business cycles and investment behavior, In: DOSI, G. et al. (Eds.). Technical change and economic theory. Londres: Pinter Publishers, 1988. p. 38-66.

ACORDO SOBRE OS ASPECTOS DA PROPRIEDADE INTELECTUAL NO COMÉRCIO INTERNACIONAL (TRIPS). Disponível em: $<$ http://www.wto.org/english/tratop e/trips e/t agm0 e.htm>. Acesso em: 20 set. 2010.

WACHOWICZ, M. Propriedade intelectual do software \& Revolução da tecnologia da informação. Curitiba: Juruá, 2004.

TRATADO DE PERFORMANCE E FONOGRAMA DA ORGANIZAÇÃO MUNDIAL DA PROPRIEDADE INTELECTUAL (WPPT). Disponível em: http://www.wipo.int/treaties/en/ip/wppt/trtdocs wo034.html. Acessado em set. de 2010.

WTC, Tratado de Copyright da Organização Mundial da Propriedade Intelectual. Disponível em: $<$ http://www.wipo.int/treaties/en/ip/wct/trtdocs wo033.html>. Acesso em: 20 set. 2010. 